\title{
Bradyrhizobium betae sp. nov., isolated from roots of Beta vulgaris affected by tumour-like deformations
}

\author{
Raúl Rivas, ${ }^{1}$ Anne Willems, ${ }^{2}$ José Luis Palomo, ${ }^{3}$ Pablo García-Benavides, ${ }^{3}$ \\ Pedro F. Mateos, ${ }^{1}$ Eustoquio Martínez-Molina, ${ }^{1}$ Monique Gillis ${ }^{2}$ \\ and Encarna Velázquez ${ }^{1}$ \\ ${ }^{1}$ Departamento de Microbiología y Genética, Universidad de Salamanca, Salamanca, Spain \\ ${ }^{2}$ Laboratorium voor Microbiologie, Vakgroep Biochemie, Fysiologie en Microbiologie, Universiteit \\ Gent, K. L. Ledeganckstraat 35, B-9000 Gent, Belgium \\ ${ }^{3}$ Centro Regional de Diagnóstico de la Junta de Castilla y León, Salamanca, Spain
}

Correspondence

Encarna Velázquez evp@gugu.usal.es

\begin{abstract}
Some varieties of sugar beet, Beta vulgaris, cultivated in northern Spain have large deformations that resemble the tumours produced by Agrobacterium species. In an attempt to isolate the agent responsible for these deformations, several endophytic slow-growing bacterial strains were isolated, the macroscopic morphology of which resembled that of Bradyrhizobium species. These strains were not able to produce tumours in Nicotiana tabacum plants and, based on phylogenetic analysis of their 16S rRNA, they are closely related to the genus Bradyrhizobium. Phenotypic and molecular characteristics of these strains revealed that they represent a species different from all Bradyrhizobium species previously described. Sequence analysis of the 16S-23S rDNA intergenic spacer region indicated that these novel strains form a homogeneous group, related to Bradyrhizobium japonicum, Bradyrhizobium liaoningense and Bradyrhizobium yuanmingense. DNA-DNA hybridization confirmed that these strains represent a novel species of the genus Bradyrhizobium, for which the name Bradyrhizobium betae sp. nov. is proposed. The type strain is $\mathrm{PL} 7 \mathrm{HG}{ }^{\top}{ }^{\top}$ (=LMG $21987^{\top}=$ CECT $\left.5829^{\top}\right)$.
\end{abstract}

The sugar beet, Beta vulgaris, has great importance in human nutrition and it is widely cultivated in Spain and other European countries. There are several commercial varieties of this plant that are obtained by natural processes of crosspollination. In Spain, one of these varieties develops unusual tumour-like deformations, the causal agent of which remains unknown (photographs of the tumour-like structure are available as supplementary material in IJSEM Online). The most probable reason for this failure to isolate the causal agent is that the tumours are old when the plants are harvested. Although we have not been able to isolate the causal agent that produces these deformations, several endophytic slow-growing bacterial strains from these tumours present in two different plants were isolated on YMA

Published online ahead of print on 9 February 2004 as DOI 10.1099/ ijs.0.02971-0.

Abbreviations: ITS, intergenic spacer; TP-RAPD, two-primers random amplified polymorphic DNA.

The GenBank accession number for the 16S rRNA gene sequence of Bradyrhizobium betae $\mathrm{PL} 7 \mathrm{HG} 1^{\top}$ is $\mathrm{AY} 372184$.

Photographs of the tumour-like deformations described here are available as supplementary material in IJSEM Online. medium (Vincent, 1970). Phylogenetic analysis of the $16 \mathrm{~S}$ rRNA molecule revealed that these strains belong to the genus Bradyrhizobium. This genus currently includes four species able to produce nodules in several legumes: Bradyrhizobium japonicum (Jordan, 1982), Bradyrhizobium elkanii (Kuykendall et al., 1992) and Bradyrhizobium liaoningense (Xu et al., 1995) establish symbioses with soybean plants. The most recently described species, Bradyrhizobium yuanmingense (Yao et al., 2002), produces nodules in Lespedeza but not in soybean. Although rhizobia are soil-inhabitants, rhizobial species are not commonly isolated from sources other than nodules. We show here that modern molecular techniques can help to identify and classify new rhizobial strains not isolated from nodules. A polyphasic study of these strains, including phenotypic and molecular taxonomic approaches, showed that these strains represent a novel species of Bradyrhizobium phylogenetically similar to B. japonicum, for which we propose the name Bradyrhizobium betae sp. nov.

For isolation of bacterial strains, several tumours present in Beta vulgaris roots were surface sterilized using a $2.5 \%$ aqueous solution of $\mathrm{HgCl}_{2}$ for $2 \mathrm{~min}$. Tumours were washed ten times in sterile water. They were then disrupted in sterile 
water and cultivated on YMA medium (Bergersen, 1961) at $28^{\circ} \mathrm{C}$ for 7 days. Four strains (PL7HG1 ${ }^{\mathrm{T}}$, TTR1, PL7HG3 and PL7HG5) were isolated from different tumours present in two plants. These strains showed a slow rate of growth and their colonies were mucoid, similar to those of B. japonicum.

To test the ability of the isolates to produce tumours, five plants per strain were inoculated between the cotyledons and the first true leaves, injecting $10 \mu \mathrm{l}$ of a suspension of about $10^{8}$ c.f.u. $\mathrm{ml}^{-1}$ prepared from a YMA plate culture grown for $48 \mathrm{~h}$. A positive control inoculated with the type strain of Agrobacterium tumefaciens, ATCC $23308^{\mathrm{T}}$, and a negative control using just sterile water were also prepared. Plants were maintained in a greenhouse for 30 days at $18-25^{\circ} \mathrm{C}$. None of the strains was able to reproduce tumours on Nicotiana tabacum, which is commonly used as a plant model of tumour growth. The strains isolated were also unable to reproduce tumours in Beta vulgaris.

Nodulation was tested using soybean (Glycine max cv. Peking) and yam bean (Pachyrrhizus ahipa), the latter a promiscuous plant that can be nodulated by several species of Rhizobium and Bradyrhizobium (Fuentes et al., 2002). B. japonicum LMG $6138^{\mathrm{T}}$ was used as a positive control. None of the isolates was able to nodulate the two plants used in this study.

PCR amplifications of nodD, nifH and virA genes were carried out using the primer pairs 5'-CTCGTCGCGCTCGACGCATTGA-3' and $5^{\prime}$-TGCCCCATGGACATGTA-3' $(\operatorname{nodD}), 5^{\prime}$-GTCTCCTATGACGTGCTCGG-3' and $5^{\prime}$ GCTTCCATGGTGATCGGGGT-3' (nifH) and 5'-ATGAATGGAAGGTATTCACCG- $3^{\prime}$ and $5^{\prime}$-GGCTCAGGCAGCTTCGCTGCG-3' (virA) under the following conditions: pre-heating at $95^{\circ} \mathrm{C}$ for $9 \mathrm{~min}, 35$ cycles of denaturing at $94^{\circ} \mathrm{C}$ for $1 \mathrm{~min}$, annealing at $54^{\circ} \mathrm{C}$ for $2 \mathrm{~min}$ and extension at $72{ }^{\circ} \mathrm{C}$ for $2 \mathrm{~min}$ and a final extension at $72{ }^{\circ} \mathrm{C}$ for $7 \mathrm{~min}$. As a positive control in amplification of symbiotic genes, strain EC-550 nodulating yam bean (Fuentes et al., 2002) was used and A. tumefaciens ATCC $23308^{\mathrm{T}}$ was used as a positive control for amplification of the virA gene. None of these genes was detected in any of the strains isolated here, whereas they were amplified from the positive controls (data not shown).

Strains were analysed by two-primers random amplified polymorphic DNA (TP-RAPD) fingerprinting according to the method previously described (Rivas et al., 2002a), using the primers $849 \mathrm{~F}$ ( $5^{\prime}$-GCCTGGGGAGTACGGCCGCA-3', Escherichia coli positions 829-849) and 1522R (5'-AAGGAGGTGATCCANCCRCA-3', E. coli positions 1509-1522). We have previously shown that TP-RAPD patterns allow differentiation among rhizobial species (Rivas et al., 2001) and, because these patterns are not strain dependent, all strains showing identical TP-RAPD pattern are considered to belong to the same species. All strains isolated in this study presented the same TP-RAPD pattern (Fig. 1) and therefore they probably belong to the same species. These

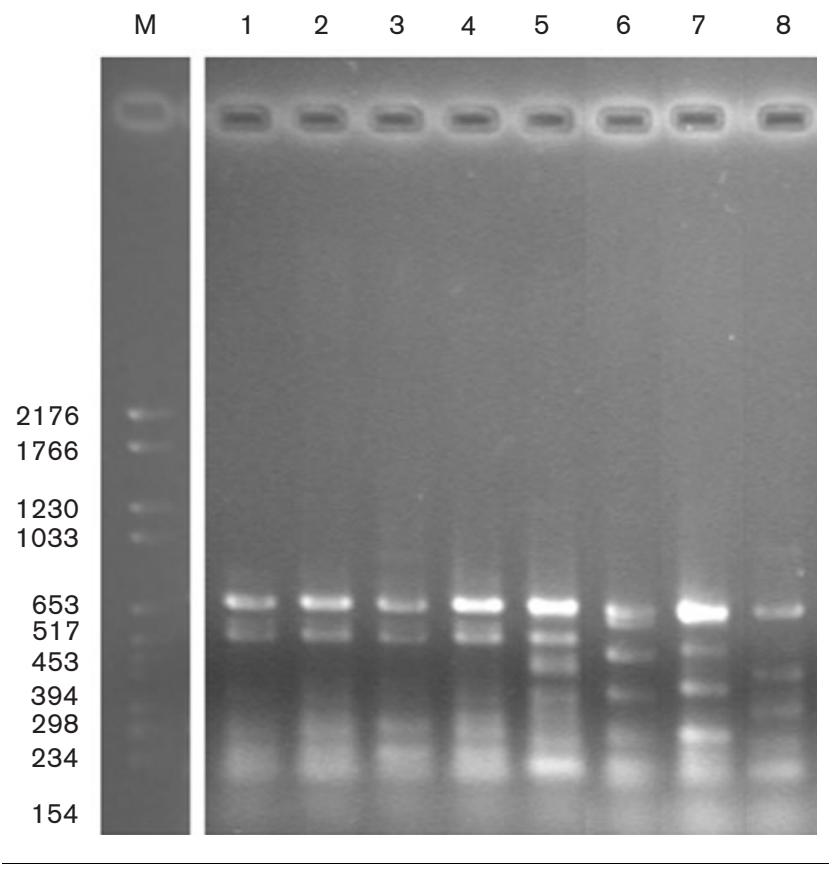

Fig. 1. TP-RAPD patterns of the strains isolated in this study (lanes 1-4) and Bradyrhizobium liaoningense LMG $18230^{\top}$ (lane 5), Bradyrhizobium japonicum LMG 6138 ${ }^{\top}$ (lane 6), Bradyrhizobium yuanmingense CCBAU $11073^{\top}$ (lane 7) and Bradyrhizobium elkanii USDA $76^{\mathrm{T}}$ (lane 8). Lane M, molecular size markers (sizes in bp).

results were confirmed from sequencing of 16S-23S rDNA intergenic spacer (ITS) regions (see below); based on these data, PL7HG1 ${ }^{\mathrm{T}}$ was considered as the type strain. The nearly complete 16S rDNA sequence from this strain was obtained according the method previously described (Rivas et al., $2002 \mathrm{~b}$ ). The sequence obtained was compared with those from the GenBank database using the FASTA program (Pearson \& Lipman, 1988), indicating that this strain is phylogenetically related to members of the genus Bradyrhizobium. Sequences of the novel isolate and related bacteria were aligned using CLUSTAL W software (Thompson et al., 1997). Distances were calculated according to Kimura's twoparameter method (Kimura, 1980). Phylogenetic trees were inferred using the neighbour-joining method (Saitou \& Nei, 1987). Bootstrap analysis was based on 1000 resamplings. The MEGA2 package (Kumar et al., 2001) was used for all analyses. The resulting neighbour-joining tree is shown in Fig. 2. The $16 \mathrm{~S}$ rDNA sequence of strain PL7HG1 ${ }^{\mathrm{T}}$ showed $99 \cdot 2 \%$ similarity to that of B. japonicum USDA110 (genospecies Ia), $99 \%$ to that of B. japonicum LMG $6138^{\mathrm{T}}$ (genospecies I), $99 \cdot 1 \%$ to that of $B$. liaoningense LMG $18230^{\mathrm{T}}, 98 \cdot 5 \%$ to that of B. yuanmingense CCBAU $11073^{\mathrm{T}}$ and $96 \cdot 4 \%$ to that of B. elkanii USDA $76^{\mathrm{T}}$.

Comparison of 16S-23S rDNA ITS regions provides a rapid means by which to assess relatedness between closely related Bradyrhizobium strains (Willems et al., 2001a, 2003). Therefore, we determined the ITS sequence of the four novel 


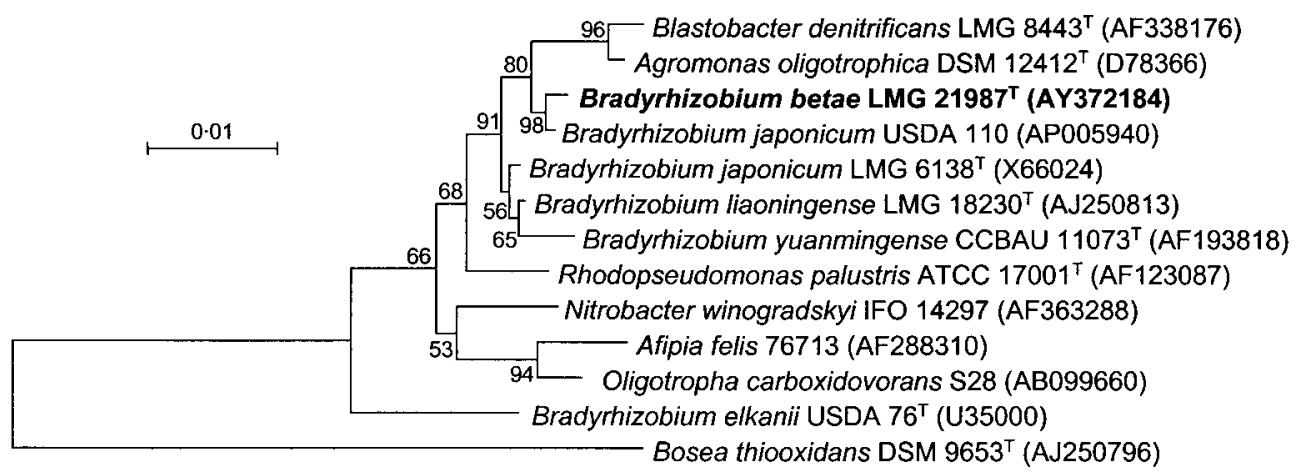

Fig. 2. Comparative sequence analysis of $16 \mathrm{~S}-23 \mathrm{~S}$ rDNA intergenic spacer (ITS) regions from Bradyrhizobium betae LMG $21987^{\top}$ and closely related species, using the neighbour-joining method. Bar, $0 \cdot 01$ changes per nucleotide position.

isolates as described by Willems et al. (2001a). The fragment obtained was $789 \mathrm{bp}$ in length for all strains. Strains TTR1, PL7HG1 ${ }^{\mathrm{T}}$, PL7HG3 and PL7HG5 had identical sequences (accession no. AJ631967). A comparison with ITS sequences of other bradyrhizobia showed that the novel strains are most closely related to $B$. japonicum genospecies Ia and I (as described by Hollis et al., 1981), B. liaoningense and B. yuanmingense. ITS sequence similarities (as calculated with BIONUMERICS version 3.0, after multiple alignment with a gap penalty of $800 \%$ and without gap penalties in the calculation of sequence similarities) of PL7HG1 ${ }^{\mathrm{T}}$ with each of these genospecies or species were $94 \cdot 2-94 \cdot 3$, $90 \cdot 7-91 \cdot 0,93 \cdot 2$ and $86 \cdot 8 \%$, respectively. Willems et al. (2003) have shown that for those bradyrhizobia closely related to B. japonicum, ITS sequence similarities of more than $95.5 \%$ indicate a genospecies-level relatedness.

Based on this information, we selected the taxa to perform DNA-DNA hybridizations using a protocol described by Willems et al. (2001b), differing only in that we used white instead of black polystyrene microplates. White plates gave higher fluorescence readings and therefore resulted in better agreement of reciprocal hybridizations. Strains PL7HG1 and TTR1 were hybridized with B. japonicum genospecies I and Ia (Willems et al., 2003) and with B. liaoningense. Each hybridization experiment (using four replicate vials) was carried out twice, and the values reported in Table 1 are means of the two experiments. Standard deviation ranged from 0 to $11 \%$ with a mean of $4 \%$. Values for combinations hybridized previously are slightly higher than those reported by Willems et al. (2001b) and this was observed consistently. Our data indicate that strains PL7HG1 and TTR1, as expected, showed almost $100 \%$ DNA-DNA relatedness to each other. They showed about $60 \%$ DNADNA hybridization with representatives of $B$. japonicum genospecies Ia and I and with $B$. liaoningense. In view of the relatively high hybridization values found here and in Willems et al. (2001b, 2003) between all Bradyrhizobium species (except B. elkanii), we propose that the novel group represented by PL7HG1 ${ }^{\mathrm{T}}$ represents a novel genospecies close to B. japonicum.

The G+C content of strains PL7HG1 ${ }^{\mathrm{T}}$ and TTR1, as determined by HPLC (see Rivas et al., 2003), was 63.7 and $64 \cdot 0 \mathrm{~mol} \%$, respectively.

Phenotypic characterization of strains from this study was based on growth with different carbon sources, as described by Velázquez et al. (2001), Yao et al. (2002) and Xu et al. (1995) and using the commercial system API 20NE according to the manufacturer's instructions (bioMérieux). The type strains of B. japonicum, B. liaoningense, $B$. yuanmingense and B. elkanii were used as references. The following antibiotics were used to test for resistance:

Table 1. Results of DNA-DNA hybridizations (\%)

\begin{tabular}{|c|c|c|c|c|c|c|c|}
\hline \multirow[t]{2}{*}{ Source of fixed DNA } & \multirow{2}{*}{$\begin{array}{c}\mathrm{G}+\mathrm{C} \text { content } \\
(\mathrm{mol} \%)\end{array}$} & \multicolumn{6}{|c|}{ Source of labelled probe } \\
\hline & & 1 & 2 & 3 & 4 & 5 & 6 \\
\hline 1. B. japonicum Ia USDA 110 & $64 \cdot 0$ & 100 & 68 & 61 & 64 & 56 & 55 \\
\hline 2. B. japonicum I LMG $6138^{\mathrm{T}}$ & $62 \cdot 8$ & 65 & 100 & 57 & 59 & 56 & 54 \\
\hline 3. B. liaoningense III LMG $18230^{\mathrm{T}}$ & $64 \cdot 2$ & 61 & 59 & 100 & 97 & 54 & 52 \\
\hline 4. B. liaoningense III LMG 18231 & $63 \cdot 4$ & 55 & 56 & 100 & 100 & 46 & 44 \\
\hline 5. B. betae sp. nov. PL7HG1 ${ }^{\mathrm{T}}$ & $63 \cdot 7$ & 63 & 63 & 52 & 49 & 100 & 98 \\
\hline 6. B. betae sp. nov. R17832 (=TTR1) & $64 \cdot 0$ & 62 & 64 & 49 & 52 & 99 & 100 \\
\hline
\end{tabular}


ampicillin $(2 \mu \mathrm{g})$, erythromycin $(2 \mu \mathrm{g})$, ciprofloxacin $(5 \mu \mathrm{g})$, penicillin (10 IU), polymyxin (300 IU), cloxacillin $(1 \mu \mathrm{g})$, oxytetracycline $(30 \mu \mathrm{g})$, gentamicin $(10 \mu \mathrm{g})$, cefuroxime $(30 \mu \mathrm{g})$ and neomicin $(5 \mu \mathrm{g})$ (all from Becton Dickinson). The basal medium was YMB (Vincent, 1970) supplemented with $0.5 \%$ yeast extract. Each antibiotic disc was added under sterile conditions to $5 \mathrm{ml}$ basal medium. All newly isolated strains had identical phenotypic characteristics but several differences from the recognized species of Bradyrhizobium (Table 2). The main differences observed between the novel species and B. japonicum are in nitrate reduction, growth in lactose and sucrose as the carbon source and resistance to polymyxin B.

The newly isolated strains can be differentiated genotypically and phenotypically from previously described species (Table 2) and we therefore propose to name the new group Bradyrhizobium betae sp. nov.

\section{Description of Bradyrhizobium betae sp. nov.}

Bradyrhizobium betae (bet'ae. N.L. gen. n. betae of Beta, a plant genus, because the organism was isolated from Beta vulgaris, sugar beet).

Gram-negative rods as for the other species of the genus. Colonies are small, pearl white in YMA at $28^{\circ} \mathrm{C}$, the optimal growth temperature. Optimum $\mathrm{pH}$ for growth is $7-7 \cdot 5$. Isolated from sugar beet tumours; they are not able to reproduce these symptoms in Beta vulgaris or Nicotiana tabacum and strains are not able to nodulate soybean or yam bean. Nitrate reduction is negative. The strains produce $\beta$-galactosidase and urease and hydrolyse aesculin. They use glucose, L-arabinose, galactose, mannose, mannitol,

Table 2. Differential characteristics between $B$. betae sp. nov. and closely related species

Species: 1, B. elkanii; 2, B. liaoningense; 3, B. yuanmingense; 4, B. japonicum; 5, B. betae sp. nov. Data for reference species were taken from Yao et al. (2002). +, Positive; -, negative; V, variable; W, weak; ND, no data available.

\begin{tabular}{|c|c|c|c|c|c|}
\hline Characteristic & 1 & 2 & 3 & 4 & 5 \\
\hline Generation time $(\mathrm{h})$ & $>6$ & $16 \cdot 4-39 \cdot 6$ & $9 \cdot 5-16$ & $>6$ & $12-16$ \\
\hline Nitrate reduction & - & ND & + & + & - \\
\hline \multicolumn{6}{|l|}{ Utilization of: } \\
\hline L-Sorbose & $\mathrm{W}$ & - & - & - & + \\
\hline D-Fructose & + & $\mathrm{V}$ & - & - & $\mathrm{W}$ \\
\hline Inositol & + & - & - & + & $\mathrm{w}$ \\
\hline Lactose & $\mathrm{V}$ & - & - & + & - \\
\hline Maltose & + & - & $\mathrm{V}$ & + & + \\
\hline Sucrose & + & - & $\mathrm{V}$ & + & - \\
\hline \multicolumn{6}{|l|}{ Resistance to: } \\
\hline Polymyxin $\left(300 \mu \mathrm{g} \mathrm{ml}^{-1}\right)$ & + & $\mathrm{ND}$ & + & - & + \\
\hline $\mathrm{NaCl}(1 \%)$ & + & ND & - & + & + \\
\hline
\end{tabular}

$\mathrm{N}$-acetylglucosamine, maltose and L-sorbose as carbon sources. Strains do not grow on lactose, L-rhamnose, trehalose, raffinose, sucrose or adonitol. All strains are resistant to cloxacillin, polymyxin $\mathrm{B}$, penicillin, gentamicin, oxytetracycline and amoxicillin. They do not grow in the presence of ciprofloxacin, cefuroxime or neomicin. Growth is weak in the presence of erythromycin. The $\mathrm{G}+\mathrm{C}$ content of the type strain is $63 \cdot 7 \mathrm{~mol} \%$.

The type strain, PL7HG1 ${ }^{\mathrm{T}}\left(=\mathrm{LMG} 21987^{\mathrm{T}}=\right.$ CECT $\left.5829^{\mathrm{T}}\right)$, was isolated from a tumour on sugar beet.

\section{Acknowledgements}

This work was supported by Junta de Castilla y León and DGCYT (Spanish Government). A. W. and M.G. are grateful to the Fund for Scientific Research - Flanders for a position as postdoctoral research fellow and for research and personnel grants, respectively. We also thank A. Peix for the correction of the English version of the manuscript.

\section{References}

Bergersen, F. J. (1961). The growth of Rhizobium in synthetic media. Aust J Biol 14, 349-360.

Fuentes, J. B., Abe, M., Uchiumi, T., Suzuki, A. \& Higashi, S. (2002). Symbiotic root nodule bacteria isolated from yam bean (Pachyrhizus erosus). J Gen Appl Microbiol 48, 181-191.

Hollis, A. B., Kloos, W. E. \& Elkan, B. E. (1981). DNA: DNA hybridization studies of Rhizobium japonicum and related Rhizobiaceae. J Gen Microbiol 123, 215-222.

Jordan, D. C. (1982). Transfer of Rhizobium japonicum to Bradyrhizobium gen. nov., a genus of slow-growing, root nodule bacteria from leguminous plants. Int J Syst Bacteriol 32, 136-139.

Kimura, M. (1980). A simple method for estimating evolutionary rates of base substitutions through comparative studies of nucleotide sequences. J Mol Evol 16, 111-120.

Kumar, S., Tamura, K., Jakobsen, I. B. \& Nei, M. (2001). Molecular Evolutionary Genetics Analysis Software. Tempe, AZ: Arizona State University.

Kuykendall, L. D., Saxena, B., Devine, T. E. \& Udell, S. E. (1992). Genetic diversity in Bradyrhizobium japonicum Jordan 1982 and a proposal for Bradyrhizobium elkanii sp. nov. Can J Microbiol 38, 501-505.

Pearson, W. R. \& Lipman, D. J. (1988). Improved tools for biological sequence comparison. Proc Natl Acad Sci U S A 85, 2444-2448.

Rivas, R., Velázquez, E., Valverde, A., Mateos, P. F. \& MartínezMolina, E. (2001). A two primers random amplified polymorphic DNA procedure to obtain polymerase chain reaction fingerprints of bacterial species. Electrophoresis 22, 1086-1089.

Rivas, R., Velázquez, E., Palomo, J. L., Mateos, P., GarcíaBenavides, P. \& Martínez-Molina, E. (2002a). Rapid identification of Clavibacter michiganensis subspecies sepedonicus using two primers random amplified polymorphic DNA (TP-RAPD) fingerprints. Eur J Plant Pathol 108, 179-184.

Rivas, R., Velázquez, E., Willems, A., Vizcaíno, N., Subba-Rao, N. S., Mateos, P. F., Gillis, M., Dazzo, F. B. \& Martínez-Molina, E. (2002b). A new species of Devosia that forms a nitrogen-fixing root-nodule symbiosis with the aquatic legume Neptunia natans (L. f.) Druce. Appl Environ Microbiol 68, 5217-5222. 
Rivas, R., Willems, A., Subba-Rao, N. S., Mateos, P. F., Kroppenstedt, R., Martínez-Molina, E., Gillis, M. \& Velázquez, E. (2003). Description of Devosia neptuniae sp. nov. that nodulates and fixes nitrogen in symbiosis with Neptunia natans, an aquatic legume from India. Syst Appl Microbiol 26, 47-54.

Saitou, N. \& Nei, M. (1987). The neighbor-joining method: a new method for reconstructing phylogenetic trees. Mol Biol Evol 44, 406-425.

Thompson, J. D., Gibson, T. J., Plewniak, F., Jeanmougin, F. \& Higgins, D. G. (1997). The CLUSTAL_X windows interface: flexible strategies for multiple sequence alignment aided by quality analysis tools. Nucleic Acids Res 24, 4876-4882.

Velázquez, E., Igual, J. M., Willems, A. \& 9 other authors (2001).

Description of Mesorhizobium chacoense sp. nov. that nodulates Prosopis alba in the Chaco Arido region (Argentina). Int J Syst Evol Microbiol 51, 1011-1021.

Vincent, J. M. (1970). The cultivation, isolation and maintenance of rhizobia. In A Manual for the Practical Study of Root-Nodules, pp. 1-13. Edited by J. M. Vincent. Oxford: Blackwell Scientific.
Willems, A., Coopman, R. \& Gillis, M. (2001a). Comparison of sequence analysis of $16 \mathrm{~S}-23 \mathrm{~S}$ rDNA spacer regions, AFLP analysis and DNA-DNA hybridizations in Bradyrhizobium. Int J Syst Evol Microbiol 51, 623-632.

Willems, A., Doignon-Bourcier, F., Goris, J., Coopman, R., De Lajudie, P. \& Gillis, M. (2001b). DNA-DNA hybridization study of Bradyrhizobium strains. Int J Syst Evol Microbiol 51, 1315-1322.

Willems, A., Munive, A., de Lajudie, P. \& Gillis, M. (2003). In most Bradyrhizobium groups sequence comparison of 16S-23S rDNA internal transcribed spacer regions corroborates DNA-DNA hybridizations. Syst Appl Microbiol 26, 203-210.

Xu, L. M., Ge, C., Cui, Z., Li, J. \& Fan, H. (1995). Bradyrhizobium liaoningense sp. nov., isolated from the root nodules of soybeans. Int J Syst Bacteriol 45, 706-711.

Yao, Z. Y., Kan, F. L., Wang, E. T. \& Chen, W. X. (2002). Characterization of rhizobia that nodulate legume species of the genus Lespedeza and description of Bradyrhizobium yuanmingense sp. nov. Int J Syst Evol Microbiol 52, 2219-2230. 